\title{
Association of complete blood count parameters with IgE levels and disease severity, atopy type in allergic rhinitis patients
}

\author{
(1) Ali Selçuk', (1) Gürhan Taşkın² \\ 1 University of Health Sciences Turkey, Regional Training and Research Hospital, Clinic of Immunology and Allergic Diseases, \\ Erzurum, Turkey \\ 2University of Health Sciences Turkey, Kanuni Training and Research Hospital, Clinic of Intensive Care, Trabzon, Turkey
}

\section{Date submitted:}

26.11.2019

Date accepted:

14.01.2020

Online publication date:

15.09.2020

\section{Corresponding Author:}

Ali Selçuk, MD, University of Health Sciences Turkey, Regional Training and Research Hospital, Clinic of Immunology and Allergic Diseases, Erzurum, Turkey draliselcuk@gmail.com

ORCID:

orcid.org/0000-0003-4089-7564

Keywords: Allergic rhinitis, allergic conjunctivitis, atopy, eosinophil, IgE, prick test

\begin{abstract}
Aims: The aim of this study was to investigate the relationship between complete blood count (CBC) parameters and atopy type, disease severity, presence of concomitant conjunctivitis in patients with allergic rhinitis (AR).
\end{abstract}

Methods: In this retrospective study, patients who presented to the immunology and allergic diseases outpatient clinic with rhinitis symptoms and who were found to have proven AR by allergy tests were included. CBC parameters and specific/total immunoglobulin E (IgE) analyses which were measured in the period of active disease were recorded.

Results: Totally 242 patients met the enrollment criteria and were included in the study. AR patients with concomitant conjunctivitis had a significantly higher eosinophil count than patients without conjunctivitis $\left(280.13 \pm 228.58 / \mathrm{mm}^{3}\right.$ vs. $231.50 \pm 199.92 / \mathrm{mm}^{3}$, respectively, $\mathrm{p}=0.047$ ). The presence of both concomitant pollen and mite atopy was significantly more frequent in the moderate/severe persistent group than in the other groups $(p<0.001)$. Serum total IgE levels were significantly higher in group with patients who had both mite and pollen atopy than in the other groups $(168.11 \pm 189.27,149.69 \pm 178.21$ and $368.53 \pm 430.31 \mathrm{IU} /$ $\mathrm{mL}$, respectively, $\mathrm{p}=0.005)$. The presence of conjunctivitis was significantly more frequent in patients with pollen atopy than in patients who did not have $(46.9 \%$ vs. $30.3 \%, p=0.021)$.

Conclusions: Although serum eosinophil count and total IgE levels are not sensitive enough in predicting the severity of AR patients, we believe that they can be helpful in diagnosis of patients with concomitant conjunctivitis and in presence of multiple aeroallergen sensitivity.

\section{Introduction}

Allergic rhinitis (AR) is an inflammatory nasal mucosa disease characterized with symptoms such as itchy nose, sneezing, rhinorrhea and nasal congestion (1). AR is the most common form of chronic rhinitis which affects almost $10-20 \%$ of the general population. It may cause sleep disorder, fatigue, nervousness, decreased school/work performance and quality of life (2).

Other than rhinitis, adult AR patients may have concurrent conjunctivitis, sinusitis and asthma. Bilateral eye itching, redness, burning, photophobia, watering and conjunctival edema may occur in allergic conjunctivitis patients (3).
In addition to the history and physical examination findings of the patients, skin prick and allergen specific immunoglobulin $E$ ( $\mathrm{IgE}$ ) tests including aeroallergens are used in AR diagnosis. AR is classified as intermittent or persistent based on the duration of the symptoms and as mild or moderate/severe based on the severity of the disease (4).

AR occurs as the result of IgE mediated type 1 hypersensitivity reaction against inhaled allergen (mostly pollen and mite). Typical symptoms and findings occur with the effect of mediators (such as histamine, leukotrienes) released from IgE-related mast cells in this inflammation accompanied by eosinophils $(2,5,6)$.

The objective of this study was to investigate whether there was a relation between allergen sensitivity, disease severity 
and complete blood count $(\mathrm{CBC})$ parameters, serum total IgE levels.

\section{Methods}

Two hundred and forty-two AR patients with at least one positive inhalant skin prick and/or allergen specific IgE test, aged $\geq 18$ years, who were admitted to University of Health Sciences Turkey, Erzurum Regional Training and Research Hospital, Immunology and Allergic Diseases outpatient clinic between February 2017 and March 2019, were included in the study. Electronic records of included patients were examined, retrospectively.The study was approved by the Local Ethical Committee (Ethical Committee of Erzurum Ataturk University Faculty of Medicine, approval number: 13.03.2019/03). The procedures were in line with the Helsinki Declaration. The procedures were in line with Helsinki Declaration. Age, gender, concurrent conjunctivitis, atopy sensitivity, $\mathrm{CBC}$ parameters and serum total IgE results of the patients were recorded. Patients were classified according to the classification system reported by ARIA (Allergic Rhinitis and its Impact on Asthma) study group (4). Patients were accordingly separated into three groups as intermittent, mild persistent and moderate/severe persistent. Patients with systemic/chronic diseases (including asthma), pregnancy, anemia/ polycythemia, leukopenia/leukocytosis, thrombocytopenia/ thrombocytosis and patients receiving systemic corticosteroid, antiinflammatory or anticoagulant drugs were excluded from the study. $\mathrm{CBC}$ and allergy tests (inhalant skin prick, serum total and specific $\operatorname{lgE}$ ) were performed simultaneously during the active period when the disease was symptomatic.

CBC parameters were studied on Sysmex XN-10 (Sysmex Comp., Kobe, Japan) device for each patient. Serum total IgE and allergen specific lgE tests were analyzed with chemiluminescence immunometric (Immulite 2000, Siemens) system for each patient. The allergen-specific IgE panel contained grassesmix, trees-mix, mite-mix and mold-mix. Histamine was used as positive control and serum physiological solutions were used as negative control for skin prick test. 15-20 minutes after the application of inhalant prick panel on the forearm, aeroallergens with a wheal $\geq 3 \mathrm{~mm}$ diameter were defined as a positive result. Inhalant skin prick test panel consisted of Dermatophagoides pteronyssinus, Dermatophagoides farinae, grasses mix, cereals mix, trees mix, weed-mix, Alternaria alternata, cockroaches, cat dander and dog dander (Lofarma Allergeni, Milan, Italy).

\section{Statistical Analysis}

All predetermined parameters were saved in a software database, then statistically analyzed (SPSS $\odot$ v20.0 software, IBM, Ili, USA. Lic.no. 10240642). Distribution of normality for quantitative data were tested by the Kolmogorov-Smirnov test. Student's t-test was used for the comparison of the normally distributed continuous numerical variables between two independent groups and the one-way ANOVA test was used for the comparison of normally distributed variables between three independent groups. The Mann-Whitney $U$ test and Kruskal-Wallis test were used when the data did not fit a normal distribution. The Pearson chi-square test or Fisher's exact test were used to assess differences of rates between the groups. The receiver operating characteristic (ROC) analysis was performed to distinguish the patients with allergic rhinitis according to atopy group and to determine the cut-off points for IgE levels. The area under the curve (AUC), cut-off point, sensitivity, specificity values were presented for IgE level. Data and results were presented as mean \pm standard deviation (SD), minimum-maximum values, numbers (\%), and also $p$ values $<0.05$ were considered as statistically significant and accordingly, confidence interval of $95 \%$ was considered.

\section{Results}

Totally 242 patients met the enrollment criteria and were included in the study. Of these, $158(65.3 \%)$ were female and $84(34.7 \%)$ were male. The mean $( \pm S D)$ age of patients was $26.43 \pm 9.18(18-59)$ years.

\section{Comparison of AR Patient Groups According to the Presence of Concomitant Conjunctivitis}

Patients were divided into 2 groups according to the presence of concomitant conjunctivitis. One hundred three (42.6\%) patients were in AR patients with conjunctivitis group, while 139 (57.4\%) were in AR patients without conjunctivitis group. The mean age of patients with and without conjunctivitis groups were similar $(25.87 \pm 9.05$ and $27.18 \pm 9.35$ years, respectively, $p=0.241)$. Gender was also similar between these groups. AR patients with concomitant conjunctivitis had a significantly higher eosinophil count than patients without conjunctivitis $\left(280.13 \pm 228.58 / \mathrm{mm}^{3}\right.$ vs. $231.50 \pm 199.92 / \mathrm{mm}^{3}$, respectively, $p=0.047$ ). The other CBC parameters and total IgE levels did not differ between the groups (Table 1).

\section{Comparison of the AR Patients According to Disease Severity Groups}

When AR patients were grouped in terms of disease severity, there were $60(24.8 \%)$ patients in the intermittent group (group 1), $94(38.8 \%)$ patients in the mild persistent group (group 2) and $88(36.4 \%)$ patients in the moderate/severe persistent group (group 3). The presence of both concomitant pollen and mite atopy was significantly more frequent in group 3 than in the other groups $(p=0.0001)$. There was no significant difference among the 3 groups in terms of demographic data, the presence of concomitant conjunctivitis and laboratory findings (Table 2).

\section{Comparison of the AR Patients According to Atopy Groups}

Of 242 AR patients, $63(26 \%)$ were in group 1 (patients with mite atopy), 137 (57\%) were in group 2 (patients with pollen 
atopy) and $42(17 \%)$ were in group 3 (patients with mite and pollen atopy). Patients with mite and pollen atopy were found to be significantly younger than the other two groups $(28.19 \pm 9.92$, $26.21 \pm 9.24$ and $24.50 \pm 7.39$ years, respectively, $p=0.045$ ). Additionally, total IgE levels were significantly higher in group
3 than in the other groups $(168.11 \pm 189.27,149.69 \pm 178.21$ and $368.53 \pm 430.31 \mathrm{IU} / \mathrm{mL}$, respectively, $\mathrm{p}=0.005$ ) (Table 3 ). In the ROC curve analysis for IgE levels to distinguish patients with both mite and pollen atopy from other atopy groups, it was observed that, for patients with total IgE levels $\geq 145.5$, the

\begin{tabular}{|c|c|c|c|}
\hline & $\begin{array}{l}\text { AR patients without } \\
\text { conjunctivitis } \\
n=139(57.4 \%)\end{array}$ & $\begin{array}{l}\text { AR patients with } \\
\text { conjunctivitis } \\
n=103(42.6 \%)\end{array}$ & $p$ value \\
\hline \multicolumn{4}{|l|}{ Demographics } \\
\hline Age & $25.87 \pm 9.05$ & $27.18 \pm 9.35$ & $0.241 \mathrm{a}$ \\
\hline Female, n (\%) & $89(64)$ & $69(67)$ & $0.632^{b}$ \\
\hline Platelet, $10^{3} / \mu \mathrm{L}$ & $285.50 \pm 62.37$ & $287.77 \pm 59.89$ & $0.844^{a}$ \\
\hline WBC, $/ \mu \mathrm{L}$ & $7605 \pm 1706$ & $7422 \pm 1808$ & $0.424^{c}$ \\
\hline Hemoglobin, g/dL & $14.84 \pm 1.50$ & $14.81 \pm 1.61$ & $0.695^{a}$ \\
\hline Hematocrit, \% & $44.74 \pm 3.90$ & $44.45 \pm 4.34$ & $0.474^{a}$ \\
\hline
\end{tabular}

\begin{tabular}{|c|c|c|c|c|}
\hline & $\begin{array}{l}\text { Group } 1 \\
\text { (Intermittent) } \\
n=60(24.8 \%)\end{array}$ & $\begin{array}{l}\text { Group } 2 \\
\text { (Mild persistent) } \\
\mathrm{n}=94(38.8 \%)\end{array}$ & $\begin{array}{l}\text { Group } 3 \\
\text { (Moderate/severe persistent) } \\
n=88(36.4 \%)\end{array}$ & $p$ value \\
\hline \multicolumn{5}{|l|}{ Demografics } \\
\hline Age, year $\pm S D$ & $25.93 \pm 9.01$ & $26.82 \pm 10.00$ & $26.35 \pm 8.43$ & $0.762^{b}$ \\
\hline Female, n (\%) & $36(60)$ & $62(66)$ & $60(68.2)$ & $0.582^{a}$ \\
\hline $\begin{array}{l}\text { Atopy groups, n (\%) } \\
\text { Mite atopy } \\
\text { Pollen atopy } \\
\text { Mite+pollen atopy }\end{array}$ & $\begin{array}{l}6(10) \\
54(90) \\
0(0)\end{array}$ & $\begin{array}{l}27(28.7) \\
56(59.6) \\
11(11.7)\end{array}$ & $\begin{array}{l}30(34.1) \\
27(30.7) \\
31(35.2)\end{array}$ & $<0.0001^{a, *}$ \\
\hline Eosinophil count, $/ \mathrm{mm}^{3}$ & $299.57 \pm 302.24$ & $227.18 \pm 174.21$ & $246.61 \pm 172.08$ & $0.278^{b}$ \\
\hline Hematocrit, \% & $44.82 \pm 4.21$ & $44.54 \pm 4.11$ & $44.57 \pm 4.01$ & $0.851 \mathrm{~b}$ \\
\hline MPV, fL & $10.38 \pm 4.11$ & $9.99 \pm 1.39$ & $10.21 \pm 1.11$ & $0.262^{b}$ \\
\hline Total IgE level, IU/mL & $228.37 \pm 251.89 \#$ & $202.58 \pm 329.42^{\#}$ & $186.58 \pm 182.44 \#$ & $0.767^{b}$ \\
\hline $\begin{array}{l}\text { WBC: White blood cell, MPV: } \\
\text { Data are given as mean } \pm \text { SD u } \\
\text { aChi-square test } \\
\text { bKruskal-Wallis test } \\
\text { "One-way ANOVA test } \\
\text { "p<0.05 } \\
\text { "Data of } 112 \text { patients with IgE }\end{array}$ & $\begin{array}{l}\text { ume, IgE: Immunoglob } \\
\text { ndicated. } \\
\text { were included }\end{array}$ & SD: Standard deviation & & \\
\hline
\end{tabular}


sensitivity was $72.7 \%$, the specificity was $70.0 \%$ and the AUC was $0.722(\mathrm{p}=0.005)$ (Figure 1).

Another important finding of our study was revealed in the comparison between AR patients according to pollen atopy. The presence of conjunctivitis was significantly more frequent in patients with pollen atopy than patients who did not have $(46.9 \%$ vs. $30.3 \%, p=0.021$ ).

\section{Discussion}

To our knowledge, this has been the first study performed on a quite high number of adult AR patients in Erzurum.

It is well-known that allergic conjunctivitis is caused by airborne allergens contacting the eye, which leads to lgEmediated allergic inflammation. In the literature, it was reported that nearly $60 \%$ of AR patients had concurrent ocular allergy. In our study, ocular allergy was seen in $42.6 \%$ of AR patients (3). In the studies published before, it has been shown that, the presence of concurrent conjunctivitis in AR patients is significantly associated with pollen atopy $(1,3)$. Similar to these data, the prevalence of conjunctivitis in AR patients with pollen atopy was higher than in those without pollen atopy in our study $(p=0.021)(1,3)$.

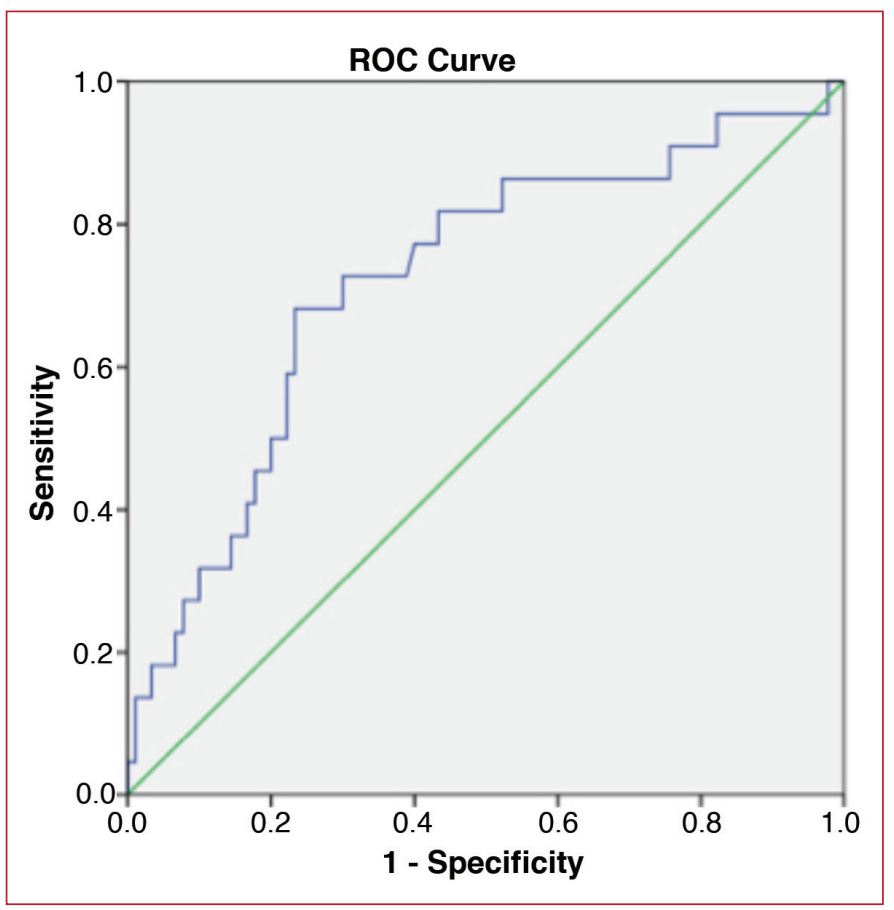

Figure 1. Receiver operating characteristic curve analysis of immunoglobulin $E$ ( $\lg E$ ) levels for mite and pollen atopy group in allergic rhinitis patients. IgE; IgE levels were significantly higher in the mite+pollen atopy group $(p=0.005)$. It was observed that for patient with lgE levels $\geq 145.5$ the sensitivity was $72.7 \%$, the specificity was $70.0 \%$ and the AUC was $0.722(p=0.005)$

IgE: Immunoglobulin E, AUC: Area under the curve, ROC: Receiver operating characteristic
Similar to the pathophysiology of atopic diseases like $A R$, eosinophils also play a significant role in ocular allergies (7). High serum ECP (eosinophil cationic protein), which is a demonstrator of the activation of systemic eosinophils, and eosinophils in tear drop and conjunctival scrapings were detected in ocular allergy patients $(8,9)$. In our study, serum eosinophil count was detected to be higher in AR patients with concurrent ocular allergy $(p=0.047)$. Based on this result, we evaluated that patients who had concurrent rhinitis and conjunctivitis with a similar pathophysiology had higher activation of systemic eosinophils. In previous studies, it was revealed that allergic conjunctivitis or allergic rhinitis patients had a higher serum eosinophil count when compared to healthy controls (10-12).

To date, the studies evaluating serum total IgE levels at the diagnosis of AR patients have reported controversial results. Burrows et al. (13) reported that the diagnosis of AR was primarily associated with skin prick test, independently of the serum total IgE levels. Also, it was reported that the measurement of serum total IgE level had low sensitivity for the diagnosis of patients with current $A R(14)$. It is below $100 \mathrm{IU} / \mathrm{mL}$ in healthy adult individuals. According to the recommendations in several previous studies, the cut-off value for an elevated IgE level was set at $100 \mathrm{IU} / \mathrm{mL}$ (15-17). In the evaluation of 112 AR patients with serum total IgE levels, while $52.7 \%$ of patients had levels above $100 \mathrm{IU} / \mathrm{mL}, 47.3 \%$ of them had normal levels. Based on these results and similar findings in literature, we believe that normal serum total IgE levels do not exclude AR diagnosis $(18,19)$. In the present study, there was not found a significant difference between AR patients with allergic conjunctivitis than those without conjunctivitis for the mean IgE levels $(p=0.269)$. In some of the previous studies, it was observed that its levels might increase in ocular allergy compared to the healthy controls $(9,11,20)$. In addition, when patients with high IgE levels were evaluated, no significant difference was found in terms of the frequency of concomitant conjunctivitis in this study $(55.3 \%$ vs. $50.8 \%$, respectively, $\mathrm{p}=0.634$ ).

In the present study, the incidence of mite allergy was $10 \%$ in the intermittent group, while it was $40.4 \%$ and $69.3 \%$ in the mild and moderate/severe groups, respectively. In a study by Dogru et al. (21) on pediatric AR patients, there was no significant difference between mild and moderate/severe disease severity groups for serum total IgE levels and eosinophil counts. Similar to this study, no significant difference was found in serum total IgE levels and eosinophil counts among the disease severity groups of adult AR patients in our study. Based on these results, it can be concluded that serum total IgE and eosinophil count were not sensitive enough in demonstrating the severity of AR patients.

In Erzurum, where this study was conducted, the humidity is low and the altitude is high and in parallel with these geographic 


\begin{tabular}{|c|c|c|c|c|}
\hline & $\begin{array}{l}\text { Group } 1 \\
\text { (Patients with mite } \\
\text { atopy) } \\
\mathrm{n}=63(26 \%)\end{array}$ & $\begin{array}{l}\text { Group } 2 \\
\text { (Patients with pollen } \\
\text { atopy) } \\
\mathrm{n}=137(57 \%)\end{array}$ & $\begin{array}{l}\text { Group } 3 \\
\text { (Patients with } \\
\text { mite+pollen atopy) } \\
\mathrm{n}=\mathbf{4 2}(\mathbf{1 7 \% )}\end{array}$ & $p$ value \\
\hline \multicolumn{5}{|l|}{ Demographics } \\
\hline Age & $28.19 \pm 9.92$ & $26.21 \pm 9.24$ & $24.50 \pm 7.39$ & $0.045^{b, *}$ \\
\hline Female, n (\%) & $46(73)$ & $87(63.5)$ & $25(59.5)$ & $0.291^{a}$ \\
\hline Conjunctivitis, n (\%) & $19(30.2)$ & $64(46.7)$ & $20(47.6)$ & $0.068 \mathrm{a}$ \\
\hline Eosinophil count, $/ \mathrm{mm}^{3}$ & $237.06 \pm 146.21$ & $257.94 \pm 252.31$ & $256.14 \pm 154.75$ & $0.369 \mathrm{~b}$ \\
\hline Platelets, $\times 10^{3} / \mu \mathrm{L}$ & $291.52 \pm 65.59$ & $285.83 \pm 59.35$ & $280.95 \pm 61.34$ & $0.937 \mathrm{~b}$ \\
\hline WBC, $/ \mu \mathrm{L}$ & $7582 \pm 1834$ & $7490 \pm 1636$ & $7566 \pm 2003$ & $0.930^{c}$ \\
\hline Hemoglobin, g/dL & $14.62 \pm 1.58$ & $14.86 \pm 1.58$ & $15.04 \pm 1.37$ & $0.269 \mathrm{~b}$ \\
\hline Hematocrit, \% & $43.96 \pm 4.07$ & $44.67 \pm 4.14$ & $45.44 \pm 3.85$ & $0.117 \mathrm{~b}$ \\
\hline MPV, fL & $10.11 \pm 1.31$ & $10.24 \pm 2.82$ & $10.01 \pm 1.55$ & $0.837 \mathrm{~b}$ \\
\hline Total IgE level, IU/mL & $168.11 \pm 189.27 \#$ & $149.69 \pm 178.21 \#$ & $368.53 \pm 430.31 \#$ & $0.005^{b, *}$ \\
\hline \multicolumn{5}{|c|}{$\begin{array}{l}\text { AR: Allergic rhinitis, WBC: White blood cell, MPV: Mean platelet volume, IgE: Immunoglobulin E, SD: Standard deviation } \\
\text { Data are given as mean } \pm \text { SD unless otherwise indicated. } \\
\text { aChi-square test } \\
\text { bKruskal-Wallis test } \\
\text { cOne-way ANOVA test } \\
\end{array}$} \\
\hline
\end{tabular}

data, pollen was the most common aeroallergen sensitivity in our study (74\% of all patients). Serum eosinophil count was detected as $252.19 \pm 213.49 / \mathrm{mm}^{3}$ in the whole study group. When serum eosinophil counts were compared between atopy groups, no significant difference was found among patients with only pollen atopy and those with only mite atopy $(p=0.359)$. Also, serum total IgE level was significantly higher in patients with both mite and pollen atopy and those with only mite atopy $(p=0.005)$. Based on these results, we evaluated that high serum total IgE values may increase more in multiple atopies occurring with the addition of mite which is a perennial allergen in patients with pollen atopy. In parallel with our results, a study by Min et al. (22) revealed that serum total IgE levels increased in line with the increasing number of allergens.

Studies published recently, which have focused on the mean platelet volume (MPV) levels as a biomarker of systemic inflammation in chronic urticaria, have shown controversial results (23-26). Additionally, there are similar studies on adult asthma patients, but studies evaluating MPV levels in AR patients are scarce (27). In the present study, there was not any relationship between serum platelet count, MPV levels and atopy type, disease severity or conjunctivitis.

This study has the inherent limitation as a retrospective study because there may be other undocumented factors that may contribute to results. Another potential limitation of this study is that its single-centered design does not allow the results to be generalized to the Turkish population.

\section{Conclusion}

Although serum eosinophil count and total IgE levels are not sensitive enough in predicting the severity of AR patients, we believe that they can be helpful in the diagnosis of patients with concomitant conjunctivitis and in the presence of multiple aeroallergen sensitivity. In addition, we think that our study may lead new methods that can help the diagnosis and predict the prognosis of AR.

\section{Ethics}

Ethics Committee Approval: The study was approved by the Local Ethical Committee (Ethical Committee of Erzurum Ataturk University Faculty of Medicine, approval number: 13.03.2019/03). The procedures were in line with the Helsinki Declaration.

Informed Consent: Retrospective study.

Peer-review: Externally peer-reviewed.

\section{Authorship Contributions}

Concept: A.S., G.T., Design: A.S., G.T., Data Collection or Processing: A.S., G.T., Analysis or Interpretation: A.S., G.T., Literature Search: A.S., G.T., Writing: A.S., G.T.

Conflict of Interest: No conflict of interest was declared by the authors. 
Financial Disclosure: The authors declared that this study received no financial support.

\section{References}

1. Bousquet J, Khaltaev N, Cruz AA, et al. Allergic Rhinitis and its Impact on Asthma (ARIA) 2008 update (in collaboration with the World Health Organization, GA(2)LEN and AllerGen). Allergy. 2008;63(Suppl 86):8-160.

2. Dykewicz MS, Hamilos DL. Rhinitis and sinusitis. J Allergy Clin Immunol. 2010;125(2 Suppl 2):103-115.

3. Bielory L. Allergic and immunologic disorders of the eye. Part II: Ocular allergy. J Allergy Clin Immunol. 2000;106:1019-1032.

4. Bousquet J, Van Cauwenberge P, Khaltaev N. Allergic rhinitis and its impact on asthma. J Allergy Clin Immunol. 2001;108(5 Suppl):147-334.

5. Borish L. Allergic rhinitis: systemic inflammation and implications for management. J Allergy Clin Immunol. 2003;112:1021-1031.

6. Orban NT, Saleh H, Durham SR. Allergic and non-allergic rhinitis. In: Middleton's allergy: Principles and practice. 7 th ed. St. Louis: Mosby; 2009:973.

7. Bonini S. Atopic keratoconjunctivitis. Allergy. 2004;59(Suppl 78):71-73.

8. Wakamatsu TH, Satake $Y$, Igarashi $A$, et al. IgE and eosinophil cationic protein (ECP) as markers of severity in the diagnosis of atopic keratoconjunctivitis. $\mathrm{Br} \mathrm{J}$ Ophthalmol. 2012;96:581-586.

9. Bonini S, Bonini S, Lambiase $A$, et al. Vernal keratoconjunctivitis revisited. a case series of 195 patients with long-term follow up. Ophthalmology. 2000;107:11571163.

10. Rutella S, Bonini St, Rumi C, Onorati P, Lambiase A, Bonini Se. Flowcytometry of peripheral blood leucocytes in vernal keratoconjunctivitis (abstract). J Allergy Clin Immunol. 1995;95:376.

11. Polido JGF, Cabral T, Perini $P$ de RC, et al. Correlations Between Allergen-Specific IgE Serum Levels in Patients With Ocular Allergy. Cornea. 2015;34:1092-1097.

12. Liu W, Xia W, Fan $Y$, et al. Elevated serum osteopontin level is associated with blood eosinophilia and asthma comorbidity in patients with allergic rhinitis. J Allergy Clin Immunol. 2012;130:1416-1418.

13. Burrows B, Martinez FD, Halonen M, Barbee RA, Cline MG. Association of asthma with serum IgE levels and skin test reactivity to allergens. N Engl J Med. 1989;320:271277.

14. Tschopp JM, Sistek D, Schindler C, et al. Current allergic asthma and rhinitis: diagnostic efficiency of three commonly used atopic markers (IgE, skin prick tests, and Phadiatop). Results from 8329 randomized adults from the SAPALDIA Study. Swiss Study on Air Pollution and Lung Diseases in Adults. Allergy. 1998;53:608-613.

15. Stone KD, Prussin C, Metcalfe DD. IgE, mast cells, basophils, and eosinophils. J Allergy Clin Immunol. 2010;125(2 Suppl 2):73-80.

16. Dati $F$, Ringel KP. Reference values for serum IgE in healthy non-atopic children and adults. Clin Chem. 1982;28:1556.

17. Wittig HJ, Belloit J, De Fillippi I, Royal G. Age-related serum immunoglobulin $\mathrm{E}$ levels in healthy subjects and in patients with allergic disease. J Allergy Clin Immunol. 1980;66:305313.

18. Bernstein IL, Li JT, Bernstein DI, et al. Allergy diagnostic testing: an updated practice parameter. Ann Allergy Asthma Immunol. 2008;100(3 Suppl 3):1-148.

19. Bañuelos Arias A del C, Montaño Velázquez BB, Campillo Navarrete MR, et al. Skin tests, serum specific IgE and total IgE in the diagnosis of patients with perennial allergic rhinitis. Rev Alerg Mex. 2003;50:147-153.

20. Insler MS, Lim JM, Queng JT, Wanissorn C, McGovern JP. Tear and serum IgE concentrations by Tandem-R IgE immunoradiometric assay in allergic patients. Ophthalmology. 1987;94:945-948.

21. Dogru M, Evcimik MF, Cirik AA. Is neutrophil-lymphocyte ratio associated with the severity of allergic rhinitis in children? Eur Arch Otorhinolaryngol. 2016;273:3175-3178.

22. Min HJ, Hong YH, Yang HS, Kim KS. The correlation of serum eosinophil cationic protein level with eosinophil count, and total IgE level in Korean adult allergic rhinitis patients. Asian Pac J Allergy Immunol. 2016;34:290-294.

23. Korniluk A, Koper-Lenkiewicz OM, Kamińska J, Kemona H, Dymicka-Piekarska V. Mean Platelet Volume (MPV): New Perspectives for an Old Marker in the Course and Prognosis of Inflammatory Conditions. Mediators Inflamm. 2019;2019:9213074.

24. Noris P, Melazzini F, Balduini CL. New roles for mean platelet volume measurement in the clinical practice. Platelets. 2016;27:607-612.

25. Vena GA, Cassano N, Marzano AV, Asero R. The Role of Platelets in Chronic Urticaria. Int Arch Allergy Immunol. 2016;169:71-79.

26. Kasperska-Zajac A, Grzanka A, Jarzab J, et al. The association between platelet count and acute phase response in chronic spontaneous urticaria. Biomed Res Int. 2014;2014:650913.

27. Sun WX, Zhang JR, Cao ZG, Li Y, Wang RT. A decreased mean platelet volume is associated with stable and exacerbated asthma. Respiration. 2014;88:31-37. 